\title{
Neurociència aplicada a l'educació. Com aprèn el cervell i quines conseqüències té
}

\section{David Bueno ${ }^{1}$ i Anna Forés ${ }^{2}$}

${ }^{1}$ Director de la Càtedra de Neuroeducació UB-EDU1ST. Secció de Genètica Biomèdica, Evolutiva i del Desenvolupament, Universitat de Barcelona

${ }^{2}$ Directora Adjunta de la Càtedra de Neuroeducació UB-EDU1ST. Departament de Didàctica i Organització Educativa, Universitat de Barcelona

dbueno@ub.edu

annafores@ub.edu

Recepció: 11/03/2021, acceptació: 18/06/2021

Resum: Fa 130 anys, el metge i investigador Santiago Ramón y Cajal va dibuixar, en un laboratori situat al carrer del Carme de Barcelona, per primera vegada i amb molta precisió, les neurones del cervell i les connexions que fan entre si. S'ha avançat molt des de llavors, i la neurociència està influint en camps del coneixement molt diversos. Segons alguns gestors científics i polítics, el segle xxi és el segle de la neurociència. Tant si és cert com si no, perquè això també ho diuen els físics pel que fa a les aplicacions de la quàntica o els informàtics respecte a la intel-ligència artificial, entre altres col-lectius de l'entorn cientificotecnològic, no hi ha cap dubte que la neurociència està de moda. I és lògic, atenent als grans avenços d'aquests darrers anys en la comprensió de la formació i el funcionament del cervell humà i la seva relació amb la vida mental, els comportaments $i$ la cognició. Un dels camps on la neurociència està establint sinergies amb força és el de l'educació. L'aplicació sinèrgica dels coneixements en neurociència al camp de l'educació ha generat una nova disciplina acadèmica, la neuroeducació. De forma succinta, es pot definir com el camp transdisciplinar de coneixement i recerca que promou la integració de les ciències de l'educació amb les que s'ocupen del funcionament i el desenvolupament neuronal i cerebral en totes les seves vessants, la neurociència. Tanmateix, es pot aplicar la neurociència a l'educació? Quines limitacions té? Amb quin objectiu? I quines dades està aportant? En aquest article es discutirà com la neurociència permet repensar l'educació i quines dades aporta perquè la pedagogia continuï optimitzant les explicacions sobre els processos d'ensenyament i aprenentatge. No debades l'educació és una de les portes principals d'accés a la cultura, i, per extensió, a la transformació de la societat.

Paraules clau: neurociència, educació, neuroeducació.

\section{Neurociencia aplicada a la educación. Cómo aprende el cerebro y qué consecuencias tiene}

Resumen: Hace 130 años, el médico e investigador Santiago Ramón y Cajal dibujó, en un laboratorio situado en la calle del Carme de Barcelona, por primera vez y con mucha precisión, las neuronas del cerebro y las conexiones que hacen entre sí. Se ha avanzado mucho desde entonces, y la neurociencia está influyendo en campos del conocimiento muy diversos. Según algunos gestores científicos y políticos, el siglo xxi es el siglo de la 
neurociencia. Tanto si es cierto como si no, porque esto también lo dicen los físicos en cuanto a las aplicaciones de la cuántica o los informáticos respecto a la inteligencia artificial, entre otros colectivos del entorno científico-tecnológico, no hay duda de que la neurociencia está de moda. Y es lógico, atendiendo a los grandes avances de estos últimos años en la comprensión de la formación y el funcionamiento del cerebro humano y su relación con la vida mental, los comportamientos y la cognición. Uno de los campos donde la neurociencia está estableciendo sinergias con fuerza es el de la educación. La aplicación sinérgica de los conocimientos en neurociencia en el campo de la educación ha generado una nueva disciplina académica, la neuroeducación. De forma sucinta, se puede definir como el campo transdisciplinar de conocimiento e investigación que promueve la integración de las ciencias de la educación con las que se ocupan del funcionamiento y el desarrollo neuronal y cerebral en todas sus vertientes, la neurociencia. Sin embargo, ¿se puede aplicar la neurociencia a la educación? ¿Qué limitaciones tiene? ¿Con qué objetivo? ¿Y qué datos está aportando? En este artículo se discutirá cómo la neurociencia permite repensar la educación y qué datos aporta para que la pedagogía continúe optimizando las explicaciones sobre los procesos de enseñanza y aprendizaje. No en vano la educación es una de las puertas principales de acceso a la cultura, y, por extensión, a la transformación de la sociedad.

Palabras clave: neurociencia, educación, neuroeducación.

\section{Neuroscience applied to education: How the brain learns and what consequences this has}

Abstract: One hundred and thirty years ago, in a laboratory located on Carrer del Carme in Barcelona, the doctor and researcher Santiago Ramón y Cajal drew, for the first time and with great precision, the neurons in the brain and the connections they made with each other. Much progress has been made since then, and neuroscience currently influences a wide range of fields of study. According to some policymakers, including many specializing in science, the 21st century is the century of neuroscience. Whether this is true or not (physicists say the same about quantum applications, just as computer scientists do with respect to artificial intelligence, and so on for other scientific and technological specialists) there is no doubt that neuroscience is in vogue. This seems logical, given the great advances of recent years in understanding the formation and functioning of the human brain and its relationship to mental life, behaviour and cognition. One of the fields in which neuroscience is currently establishing strong synergies is education. The synergistic application of neuroscientific knowledge to the field of education has generated a new academic discipline: neuroeducation. This can be succinctly defined as the transdisciplinary field of knowledge and research that promotes the integration of educational sciences with those that deal with neural functioning as well as neuronal and cerebral development in all its aspects (in other words, neuroscience). However, to what extent can neuroscience be applied to education? What are its limitations? For what purpose? And what data does it provide? This article will discuss how neuroscience makes it possible to rethink education, and what data this field provides so that pedagogy can continue to optimise explanations of both teaching and learning processes. Education's role as one of the main gateways to culture, and by extension to the transformation of society, must also be taken into account.

Keywords: neuroscience, education, neuroeducation.

\section{LA RECERCA EN NEUROEDUCACIÓ: LÍMITS I AVANTATGES}


La neurociència és la disciplina científica que estudia el sistema nerviós en tots els seus aspectes. Això és, la seva estructura molecular, cel-lular, anatòmica i funcional; les patologies que el poden afectar i les teràpies i la farmacologia per tractar-les; el desenvolupament embrionari i fetal i els canvis que es van produint en el decurs de la vida; l'evolució del sistema nerviós des de l'origen dels metazous fins a les espècies actuals, i la interacció de la genètica, l'epigenètica i l'ambient per generar la ment humana. És a dir, el cervell com a base biològica de la cognició i la conducta. La neurociència, com a disciplina científica experimental, està subjecta de manera estricta al mètode científic. Per a una descripció dels principals mètodes d'estudi en neurociència experimental, vegeu Harrington (2020). Ara bé, per a una descripció molt més senzilla però, tanmateix, molt útil, que permet veure si una proposta suposadament científica segueix el mètode científic, es pot consultar La ciència en $4 D$ (Purroy, 2015).

S'utilitzen diverses aproximacions, segons l'estudi a realitzar. En el cas concret de la neuroeducació, sovint cal monitoritzar l'activitat cerebral en situacions particulars, com per exemple quan s'està treballant amb motivació intrínseca o per simple obligació, per curiositat o per por (por del suspens o de l'amonestació, per exemple), etcètera. Una de les tècniques més habituals, no invasiva (és a dir, que no altera els processos mentals), és la ressonància magnètica funcional. Permet detectar canvis en el flux de sang oxigenada en les diferents zones del cervell, fet que es correlaciona amb la seva activitat (per a una revisió de les tècniques més habituals, podeu veure Bueno, 2019a). També cal considerar que el mètode científic no només utilitza aproximacions experimentals, sinó també correlacionals, comparatives de causa-efecte, observacionals, històriques, amb enquestes sociològiques, etcètera.

Quan s'aplica a l'educació, tanmateix, cal tenir present les particularitats d'aquesta altra disciplina acadèmica, principalment el fet de treballar amb persones $\mathrm{i}$, més concretament, molt sovint amb infants i adolescents (per a una descripció de mètodes en recerca educativa, vegeu Juste, 2012; per a una descripció bàsica de les particularitats en recerca educativa respecte al mètode científic experimental, vegeu Bueno, 2019a; Ruiz, 2020). Per començar, per qüestions ètiques, i per la complexitat de variables que entren en joc, no és possible realitzar determinats estudis, en concret aquells que poguessin suposar algun tipus de problema per al desenvolupament cognitiu o emocional dels infants o adolescents. Això és especialment rellevant quan s'estableixen els grups control i quan es pretén demostrar els efectes negatius de determinades intervencions pedagògiques. En aquests casos l'única possibilitat èticament viable consisteix a realitzar estudis de correlació, identificant persones que per qüestions alienes a la mateixa investigació s'hagin vist sotmeses a determinats processos educatius.

A més, la gran diversitat sociocultural, econòmica i de contextos ambientals fa que sigui difícil generalitzar a partir d'estudis específics circumscrits a una tipologia concreta d'alumnat. Una intervenció que pot ser molt efectiva en una escola d'una zona rural de Catalunya, per exemple, pot tenir una efectivitat escassa o nul.la en un centre educatiu d'una gran ciutat o d'un altre país. També acostuma a ser complicat establir quins paràmetres educatius o quins èxits cognitius o emocionals es valoren, i cal considerar sempre que cada docent és percebut pels alumnes d'una manera pròpia, i que, per consegüent, la simple presència d'un docent o un altre pot modificar lleugerament els resultats o la seva interpretació. Tanmateix, malgrat aquestes limitacions, que cal tenir presents, i que obliguen a repetir els estudis més interessants en cada situació concreta per comprovar-ne l'efectivitat, l'aplicació dels coneixements i recerques en neurociència al camp de l'educació estan proporcionant dades molt interessants que cal tenir en compte en el disseny de noves estratègies pedagògiques i en la revisió o consolidació de les ja establertes. De fet, com va identificar el filòsof de la ciència Thomas Kuhn a L'estructura

Neurociència aplicada a l'educació. Com aprèn el cervell i quines consequiències té David Bueno i Torrens, Anna Forés (2021) Llengua, Societat i Comunicació, núm. 19 http://revistes.ub/index.php/LSC/ 
de les revolucions científiques (2008), els avenços més interessants neixen dels territoris de frontera entre diverses disciplines acadèmiques.

\section{L'INSTINT D'APRENDRE}

El cervell és l'òrgan del pensament. És a dir, és on s'originen i des d'on es gestionen totes les capacitats mentals i cognitives, entre les quals s'inclou la capacitat d'aprenentatge. Una primera pregunta que és transcendental per a la neuroeducació és si el fet d'aprendre és una construcció cultural de l'espècie humana o bé, alternativament, un instint associat a la biologia de les persones. Si fos una construcció cultural, un dels objectius principals de l'educació hauria de ser ensenyar als alumnes com han d'adquirir coneixements. En canvi, si fos un instint biològic arrelat al funcionament propi del cervell, el que caldria fer és entendre com funciona aquest instint i a quines causes biològiques $\mathrm{i}$ evolutives obeeix, per poder-ne treure el treure el rendiment més òptim a través de propostes educatives que l'aprofitessin al màxim.

La resposta a aquestes preguntes retòriques és que aprendre és un instint biològic. Culturalment, decidim què considerem que cal aprendre, quins coneixements cal anar incorporant durant les diverses etapes educatives, i bastim el sistema educatiu i els currículums en funció d'això. Però el fet d'aprendre en si mateix és un instint inevitable. Hi ha diverses proves que ho corroboren. Per exemple, s'ha vist que els infants en l'etapa preverbal utilitzen raonaments filosòfics com el sil-logisme disjuntiu (Mody i Carey, 2016), i també el mètode científic (Cook i col., 2011) de manera espontània com a mecanismes d'adquirir coneixements per anticipar situacions. Aquest és el primer punt clau de com aprèn el cervell i de quines conseqüències té.

Com a espècie biològica, una de les adaptacions més importants que tenim i que afavoreixen la nostra supervivència és, precisament, la capacitat d'aprenentatge. Aprenem per instint, i aquest instint ens commina a adquirir coneixements del nostre entorn, especialment, però no únicament, de l'entorn social, amb una finalitat específica: poder-nos anticipar als canvis d'aquest entorn. Vivim en un entorn dinàmic i canviant, i també incert. Tant el fet de poder-nos anticipar a les amenaces, per evitar-les, com també d'anticipar-nos a les oportunitats, per estar amatents quan arribin i poder-les aprofitar, incrementa la probabilitat de supervivència a nivell d'individus i de l'espècie en el seu conjunt (per a una descripció divulgativa d'aquest concepte, podeu veure Bueno, 2020). Aprendre és un instint lligat a la supervivència de la nostra espècie.

Una de les proves que ho recolza és el fet que qualsevol comportament que estigui vinculat a la supervivència el cervell el recompensa amb sensacions de plaer i de benestar, la qual cosa ens commina a repetir-lo. Menjar, per exemple, genera un cert plaer, perquè, si no mengéssim, moriríem de gana. Aquest plaer, sumat, per descomptat, a la incomoditat que produeix tenir gana, ens impulsa a menjar quan ho necessitem. També aparellar-nos genera plaer, perquè, si no ens reproduíssim, l'espècie s'extingiria. I també el fet d'estar amb altres persones, perquè som una espècie social que basa part de la seva supervivència en la col-laboració. Doncs bé, s'ha vist que aprendre coses noves també activa els mateixos mecanismes cerebrals associats a les sensacions de recompensa, de benestar i plaer (per a descripcions generals d'aquest concepte, podeu veure Bueno, 2017, 2019b).

Per exemple, s'ha demostrat que als infants, quan estan aprenent a parlar i veuen que cada paraula nova que aprenen és reconeguda pel seu entorn, això els provoca una descàrrega de dopamina (que és el neurotransmissor associat al plaer, a la motivació i a l'optimisme), que, a través de les sensacions de recompensa que els genera, els estimula a prendre una nova paraula (Ripollès i col., 2014). I així una darrere l'altre. De vegades, però, el plaer per aprendre es va perdent amb l'edat, la qual cosa deslliga el sistema

Neurociència aplicada a l'educació. Com aprèn el cervell i quines consequiències té David Bueno i Torrens, Anna Forés (2021) Llengua, Societat i Comunicació, núm. 19 http://revistes.ub/index.php/LSC/ 
educatiu de l'instint biològic que aprofita. Per això, precisament, és important conèixer de quina manera el cervell prioritza els coneixements que adquireix, per aprofitar aquest sistema des de l'educació.

\section{COM APRÈN EL CERVELL: DE LA REFLEXIÓ A L'EMOCIÓ (I VICEVERSA)}

Aprendre és, com s'ha dit, un instint biològic lligat a la supervivència. Tot allò que s'aprèn, tant si són conceptes com actituds o habilitats, va quedant fixat al cervell en connexions neuronals. Hi ha una estructura anomenada hipocamp, que forma part del sistema límbic, un dels més primitius des de la perspectiva evolutiva, que és l'encarregada de gestionar la memòria (vegeu la Figura 1), però aquesta resideix en connexions per tot el cervell. Cada nou coneixement o experiència que queda registrat en la memòria genera un patró de connexions neuronals. Tanmateix, quan es viu una experiència o s'adquireix un coneixement sobre el qual ja es tenia certa informació prèvia o relacionada, el cervell incorpora connexions noves a les que ja tenia, de forma que els aprenentatges van quedant vinculats entre ells. Això té diverses conseqüències interessants. D’una banda, permet incrementar progressivament el nivell de coneixements, fent que no es mantinguin com parcel-les aïllades, sinó que es vagin construint com un tot. En aquest sentit, s'ha vist que com més àrees del cervell queden vinculades per un mateix aprenentatge, millor es recorda i, sobretot, amb més eficiència es pot utilitzar. És a dir, el cervell prioritza els aprenentatges transversals i contextualitzats, la qual cosa hauria de servir per dirigir les estratègies pedagògiques cap a aquesta fita, com ho demostren metodologies com l'aprenentatge basat en problemes (ABP) servei (Tan, 2021) o l'aprenentatge (Felten i col., 2006).

FIGURA 1. Principals zones del cervell esmentades a l'article.

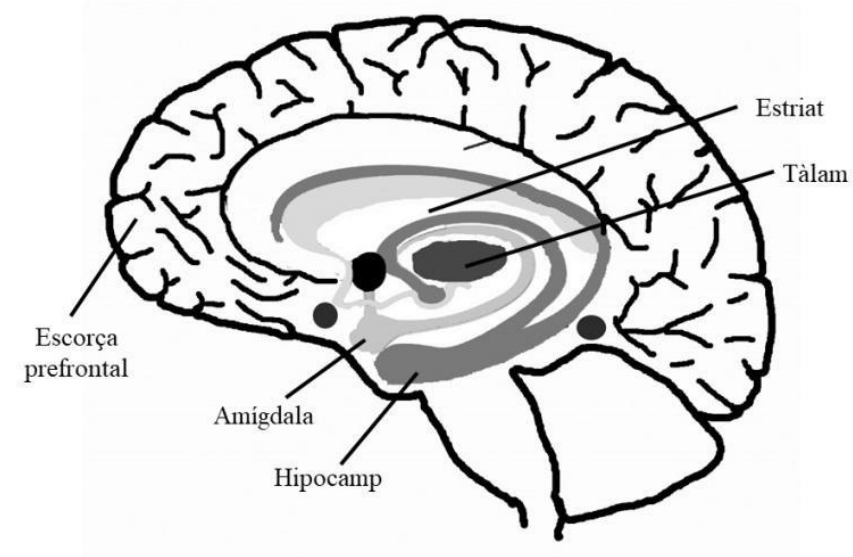

Font: modificat de Bueno (2019a).

D’altra banda, però, aquest sistema de construcció dels aprenentatges implica que, si en algun moment s'ha adquirit un aprenentatge incorrecte o ineficient, es mantindrà al cervell i servirà de base a nous coneixements relacionats, malgrat que aquest pugui ser ja correcte. A poc a poc, a mesura que es vagin adquirint coneixements correctes, quedarà minoritzat, però es mantindrà. Això implica que en algunes situacions podrà continuar condicionant l'ús d'aquests conceptes, i explica per què és tan difícil deslliurar-se dels

Neurociència aplicada a l'educació. Com aprèn el cervell i quines consequiències té David Bueno i Torrens, Anna Forés (2021) 
preconceptes basats en notícies falses (les anomenades fake news). Un cop s'implanten, tenen tendència a romandre dins el cervell (Rapp i Salovich, 2018); dit d'una altra manera: aprendre és molt senzill, però desaprendre és complex.

Un altre aspecte important que la recerca neuroeducativa destaca és la funció de les emocions en els aprenentatges (Bueno, 2021; Martin i Ochsner, 2016). Les emocions, que es generen en una estructura també molt primitiva del cervell que s'anomena amígdala i que està al costat de l'hipocamp, formant part també del sistema límbic, són patrons de conducta que es generen de manera instintiva davant una situació que requereixi una resposta immediata. Qualsevol resposta reflexiva és més lenta, i quan cal immediatesa molts cops no arribarien a temps. Tenim moltes emocions, però n'hi ha sis que són bàsiques: la por, la ira, el fàstic, la tristesa, l'alegria i la sorpresa. Totes són necessàries -de fet, imprescindibles- per sobreviure, atès que confereixen aquesta capacitat de resposta immediata. Això fa que qualsevol aprenentatge que tingui contingut emocional el cervell l'incorpora amb molta més eficiència, atès que considera que és clau per sobreviure. Dit d'una altra manera, qualsevol coneixement, per molt racional que sigui, és important transmetre'l també a través de continguts emocionals. En aquest sentit, cal dir que l'estat emocional amb què s'adquireixen coneixements nous també genera connexions neuronals, que hibriden amb les connexions d'allò que s'està aprenent. Què s'aprèn i com s'aprèn conforma un tot dins el cervell.

Això fa que, en el camp neuroeducatiu, no totes les emocions siguin equivalents. La por, per exemple, de suspendre, de fer el ridícul, etcètera, també pot afavorir els aprenentatges, però fa que tot allò que s'aprèn sota aquest estat emocional quedi vinculat a les sensacions incòmodes que el propicien. I aquest fet té conseqüències a mitjà i a llarg termini, atès que condicionarà el caràcter i les respostes d'aquesta persona, que s'esbiaixaran. La por és una emoció que es desencadena davant una situació que percebem com una amenaça, i ens commina a amagar-nos o fugir. Aprendre amb por, per tant, propicia que costi més afrontar-se a nous coneixements i reptes, atès que afavoreix la «fugida».

Les emocions que es consideren més útils per fixar aprenentatges eficients que mantinguin la mentalitat de creixement, és a dir, la capacitat de continuar aprenent i creixent no només a com a professionals, sinó també com a persones, són l'alegria i la sorpresa (o la curiositat). L'alegria és una emoció que transmet confiança, i aprenem de qui confiem. A més, contribueix a gestionar l'estrès, ja que les situacions noves no es perceben, si més no inicialment, com a amenaçadores, sinó com a possibles oportunitats. I la sorpresa, que es relaciona directament amb la curiositat, activa l'atenció a través d'una altra zona del sistema límbic, el tàlem (vegeu la Figura 1), afavoreix la motivació (a través del neurotransmissor dopamina, del qual hem parlat abans) i genera sensacions de recompensa i plaer (també a través de la dopamina i d'una altra zona del sistema límbic anomenada estriat; vegeu la Figura 1; per a llibres que abordin aquestes qüestions de manera extensa, podeu veure Mora, 2013; Bueno 2017, 2019a; Carballo i Portero, 2018; Ruiz, 2020)

Finalment, un altre dels molts aspectes importants que destaquen els treballs en neuroeducació és el control de les funcions executives per a la construcció de personalitats proactives i transformadores (Anderson i col., 2008). Les funcions executives, que depenen de xarxes neuronals que es troben a l'anomenada escorça prefrontal del cervell (Figura 1), comprenen un conjunt de capacitats cognitives imprescindibles, com són la capacitat de planificar futurs alternatius, reflexionar sobre els pros i contres d'aquestes possibilitats, prendre decisions basades també en aquestes reflexions i no només en la immediatesa del moment, adequar el nostre comportament per portar a la pràctica les decisions que prenem (la qual cosa implica gestió emocional

Neurociència aplicada a l'educació. Com aprèn el cervell i quines consequiències té David Bueno i Torrens, Anna Forés (2021) Llengua, Societat i Comunicació, núm. 19 http://revistes.ub/index.php/LSC/ 
per reconduir racionalment els estats emocionals quan creiem que ens poden ser tòxics) $\mathrm{i}$ flexibilitzar les nostres respostes (una capacitat cognitiva que s'anomena flexibilitat cognitiva) per poder-les adaptar i readaptar als canvis que es van produint. Són les funcions cognitives més complexes, i malgrat que van madurant a poc a poc des de la infantesa, són les darreres a completar el procés de maduració. En aquest sentit, la manera de contribuir des de l'educació a la seva maduració és facilitant ambients en què els alumnes, de qualsevol edat, les puguin utilitzar. Cada vegada que deixem temps als estudiants perquè planifiquin, reflexionin, decideixin, etcètera, cada vegada que els ajudem amb el nostre guiatge perquè realitzin aquestes activitats, s'activen les xarxes neuronals que les sustenten, i això fa que s'enforteixin i estableixin connexions noves que incrementen la seva eficàcia. Sempre adaptat a l'edat dels alumnes, ja que aquestes capacitats van madurant lentament.

\section{A MOdE D’EPÍleG: EL FUTUR DE LA NEUROEDUCACIÓ}

De la interacció sinèrgica de la neurociència i l'educació, d'aquest nou camp de coneixement que es mou a la frontera entre aquestes dues disciplines acadèmiques, estan sorgint noves idees, moltes de les quals reforcen el que des de la pedagogia moderna ja es postula des de fa dècades, com, per exemple, la importància del joc i de les emocions, la necessitat de moviment i de sensorialitat, la importància del treball col-laboratiu i de la implicació social, etcètera (vegeu Bueno, 2012, 2019a; Bueno i Forés, 2021; Ruiz, 2020 per a revisions i bibliografia general sobre el tema). I també altres de noves, com la funció que poden tenir dosis moderades i molt ben administrades d'estrès sobre l'atenció (per exemple, en el treball per reptes o desafiaments, trobar solucions a diferents problemes, les scape rooms, etc.), el paper de la sorpresa i la motivació, el valor de l'esforç quan es veu satisfet sobre les sensacions de recompensa, la relació de la motivació amb l'optimisme a nivell de neurotransmissors, etcètera.

De l'àmbit de les neurociències, la neuroeducació té en compte coneixements sobre el funcionament del cervell, especialment relacionats amb els processos de plasticitat subjacents a les funcions cognitives superiors, com l'atenció i la memòria, o bé les bases neurobiològiques de la conducta i les emocions. De l'àmbit de l'educació, se centra principalment en el desenvolupament de teories i pràctiques pedagògiques que expliquen com funcionen els processos d'ensenyament i d'aprenentatge atenent les diverses metodologies d'aula, la didàctica, els materials, les competències bàsiques o les habilitats docents (per exemple, pel que fa a la mirada i les expectatives vers els estudiants), entre d'altres. I també inclou elements del camp de la psicologia, com els conceptes i les teories sobre el funcionament de la cognició i de la conducta humana, i de la sociologia, com els factors d'interacció social.

Arribats a aquest punt, ja podem respondre les preguntes que de forma retòrica plantejàvem a l'inici de l'article. De forma resumida, es pot aplicar la neurociència a l'educació? La neuroeducació és, encara, una disciplina molt jove i, de moment, la major part d'estudis de què es disposa són de recerca bàsica en contextos de laboratori. Encara hi ha, per tant, una mancança molt important de recerques aplicades en contextos naturals d'aprenentatge, i moltes de les hipòtesis i teories es basen en recerques correlacionals. Així, doncs, si bé la neuroeducació està començant a projectar un escenari d'optimització i d'evolució pedagògica molt prometedor, amb un nombre creixent d'aplicacions exitoses a les aules (Bueno i Forés, 2021), cal ser conscients que és un àmbit de recerca que encara té molt camí per recórrer, i que encara manquen molts experiments «de camp» (Carballo, 2016; Bueno, 2019a; Ruiz, 2020). Per aquest motiu és comprensible l'existència d'un cert escepticisme per part d'alguns científics i pedagogs en relació amb les aportacions reals de la neurociència al disseny de pràctiques pedagògiques

Neurociència aplicada a l'educació. Com aprèn el cervell i quines consequiències té 
específiques. I també propicia l'aparició de creences errònies, els anomenats «neuromites» (Howard-Jones, 2014; Forés i col., 2015), que cal anar desterrant, com la hipòtesi de les intel-ligències múltiples (la qual cosa no vol dir que la intel-ligència no estigui formada per moltes facetes diferents que cal reconèixer), la creença que només fem servir un 10 \% del cervell (el fem servir tot, però no de manera simultània) o les propostes que es basen en estils cognitius aparentment contraposats.

\section{REFERÈNCIES BibliogrÀFiques}

Anderson, V., Anderson, P. J., Jacobs, R. i Spencer, M. (2008). Development and assessment of executive function: From preschool to adolescence. Executive Functions and the Frontal Lobes. Londres: Psychology Press

Bueno, D. (2017). Neurociència per a educadors. Barcelona: Rosa Sensat.

BuEno, D. (2019a). Neurociencia aplicada a la educación. Madrid: Editorial Síntesis.

BuEno, D. (2019b). Trenca-t'hi el cap. La cultura com a motor de la re-evolució cerebral. Barcelona: Editorial Destino.

BuEno, D. (2020). L'art de persistir. Barcelona: Ara Libres.

BuENo, D. i Forés, A. (coord.) (2021). La pràctica educativa con mirada neurocientífica. Barcelona: Editorial Horsori.

BuEno, D. (2021). La Neurociencia como fundamento de la Educación Emocional. Revista Internacional de Educación Emocional y Bienestar 1(1): 47-61.

Carballo, A. (2016). Neuroeducació: De la neurociència a l'aula. Guix d'Infantil 86: 11-14.

Carballo, A. i Portero, M. (2018) 10 ideas clave. Neurociencia y educación: aportaciones para el aula. Barcelona: Editorial Graó.

Cook, C., Goodman, N. D. i Schulz, L. E. (2011). Where science starts: spontaneous experiments in preschoolers' exploratory play. Cognition 120: 341-349.

Felten, P., Gilchrist, L. Z. i Darby, A. (2006). Emotion and Learning: Feeling Our Way toward a New Theory of Reflection in Service-Learning. Michigan Journal of Community Service Learning 12(2): 38-46.

Forés, A., Gamo, J. R., Guillén, J. C., Hernández, T., Ligioiz, M., Pardo, F. i Trinidad, C. (2015). Neuromitos en educación. Barcelona: Plataforma Editorial.

Forés, A. i Bueno, D. (2019). Hay una fórmula para saber si una metodología educativa tiene solvencia científica. The Conversation 20/02/2019.

Greene, J. D., Nystrom, L.E., Engell, A.D., Darley, J.M. i Cohen, J.D. (2004). The neural bases of cognitive conflict and control in moral judgment. Neuron 44: 389-400.

Harrington, M. E. (2020). The Design of Experiments in Neuroscience (3rd edition). Cambridge: Cambridge University Press.

Howard-Jones, P. A. (2014). Neuroscience and education: myths and messages. Nat. Rev. Neurosci. 15: 817-824.

Martin, R. E. i OchsneR, K. N. (2016). The neuroscience of emotion regulation development: implications for education. Current Opinion in Behavioral Sciences 10: 142-148. 
Mody, S. i CAREY, S. (2016). The emergence of reasoning by the disjunctive syllogism in early childhood. Cognition 154: 40-48.

MorA, F. (2013). Neuroeducación: Solo se puede aprender aquello que se ama. Madrid: Alianza Editorial.

Pérez-Juste, R. (2012). Métodos y diseños de investigación en educación. Madrid: Ediciones UNED.

Purroy, J. (2015). La ciència en 4D. Mètode 05/02/2015.

Kunn, T. (2008). L'estructura de les revolucions científiques. Barcelona: Obrador Edendum. Traducció de: The Structure of Scientific Revolutions, 1996.

Rapp, D. N. i Salovich. N. A. (2018). Can't We Just Disregard Fake News? The Consequences of Exposure to Inaccurate Information. Policy Insights from the Behavioral and Brain Sciences 5(2):232-239.

Redolar, D. (2014). Neurociencia Cognitiva. Madrid: Editorial Médica Panamericana.

Ripollés, P., Marco-Pallarés, J., Hielscher, U., Mestres-Missé, A., Tempelmann, C., Heinze, H. L., Rodríguez-Fornelis, A. i Noesselt, T. (2014). The Role of Reward in Word Learning and Its Implications for Language Acquisition. Curr. Biol. 24: 2606-2611.

Ruiz, H. (2020). ¿Cómo aprendemos? Una aproximación científica al aprendizaje y la enseñanza. Barcelona: Editorial Graó.

TAN, O. S. (2021). Problem-based Learning Innovation. Singapur: Cengage Learning.

WAGENSBERG, J. (2006). A más cómo, menos por qué. Barcelona: Tusquets Editores. 